\title{
Research on the Construction of Joint Management System for College Students' Ideal and Belief Education in the New Era
}

\author{
Jing Cang*
}

\begin{abstract}
School of economics, Shandong technology and business university, Yantai, Shandong 264005, China
\end{abstract}
*Corresponding author. Email: 2993933693@qq.com

\begin{abstract}
Ideal and belief education for college students belongs to profound level of ideological education which is a usually old but always young issue. Facing the great changes unseen in a century, new challenges and dilemma existing in college students' ideal and belief education must be clearly recognized. In the new era, responsibility of this education should not be taken by university solely. The education community and supporting system for joint management which consist of governments, universities, society and environment must be constructed. Four coordination mechanisms including education institution, education subjects, education contents and education environment are of necessity to be established. With the complete system, the strong education situation and coordination effects under the condition of whole society joint management can be achieved to ensure college students strengthen their ideal and belief, grow up healthily both in body and mental.
\end{abstract}

Keywords: Ideal and belief education, Joint management system, Coordination mechanism, The new era, College students.

\section{INTRODUCTION}

In October of 2019, the seventh part of Decision on Major Issues Concerning Upholding and Improving Socialism with Chinese Characteristics and Modernizing the State Governance System and Capacity clearly pointed out that ideal and belief education will be normalized and institutionalized. The group of college students are the future of motherland and the hope of nationality. They need attic ideal and faith on socialism with Chinese characteristics. For college students in the new era, constructing a jointly managing system of education is helpful of forming the state of jointly management, strengthening the core socialist values and patriotic beliefs, establishing the pursuit for the common cause of socialism with Chinese characteristics and upgrading the effects of ideal and belief education. Thus, college students will have lofty ideals and noble faith. They can bare the burden and assume the responsibility of serving the people and building a better life and world.

\section{LITERATURE REVIEW}

Ideal and belief are the basis of morality education. College students' ideal and belief education which belongs to deep level of ideological education is always one of the focus points in teenagers research. Since 2012, the research on college students' ideal and belief in China covered the aspects of existing problems, realizing paths and mechanism, system constructing, etc. They can be combed logically as following.

A. The main problems existing in the current education of college students' ideal and belief manifest as follows. Firstly, the lack of education in traditional culture leads to college students' weak sense of ideal and belief. Secondly, there exists the imperfectness of college students' ideal and belief education system. Thirdly, the teaching content is monotonous and lack in emotional experience. Fourthly, the teaching channel and method are singleness and the theory and practice are in disconnection. Fifthly, the teaching mechanism is unsound and works sluggishly[1][2][3][4][5].

B. Innovation and consummating teaching path are the keys of college students' ideal and belief education. 
Firstly, the teaching channels should be expanded through integrating ideal and belief education into major class. Secondly, practising activities should be enhanced through integrating ideal and belief education into social practices. Thirdly, the teaching connotation should be enriched through blending ideal and belief education into daily life. Fourthly, cultural identity should be deepened through strengthening traditional culture education. Fifthly, the wholesome atmosphere of teaching should be built through establishing click-and-mortar mechanism. The teaching effect should be enhanced through intensifying the icons leading mechanism, establishing and perfecting social and environment mechanism[6][7][8][9][10].

C. Systematization research on college students' ideal and belief education should be emphasized. Firstly, college students' ideal and belief education system consisting of teaching lines, teaching contents, teaching resources, teaching methods and teaching support should be constructed in three levels including ideological cognition, practice operation and mechanism support. Secondly, college students' ideal and belief education should be persistent, normalized and more scientific in all aspects[1][11][12][13][14].

From the view of time lines and research contents of the above literature, although the status quo, existing problem, realizing path and mechanism of college students' ideal and belief education have been analyzed deeply by scholars and the construction of the ideal and belief education system also was discussed to some extent, but there exists a lot of research space in the characteristics of times, the breadth, the depth and systematicness for college students' ideal and belief education.

A. Because college students' ideal and belief is restricted and driven by the philosophy, values and outlook on the world and life, affected and disturbed by the transition of times and environment, also induced and confused by various social thoughts, it is always an age-old but also a new topic changing with the times, complexity and persistence during the process of sprouting, formulating and strengthening.

B. Facing the new situation with constant infiltration of the variety of internet information and the challenges with the great changes unseen in a century of human society, college students' ideal and belief education which is not any more the sole responsibility taken by university needs outer and inner diversified supports of jointly management, perfect supporting system, and new method and innovative train of thoughts.

C. The problem of college students' ideal and belief education in the new era is a huge social systematic project which needs comprehensive and overall process survey from the perspective system theory. It also needs coordination approach to guide the construction of system and mechanism of college students' ideal and belief education.

For the college students in the new age, ideal and belief education is confronted with new challenges by the huge changes unseen in a century. It needs the whole society's participation and higher attention other than colleges takes the task alone. Therefore, the topics of how to construct supporting systems and coordination mechanism for college students' ideal and belief education with jointly management have significant theoretical meanings and realistic values.

\section{METHODOLOGY}

\subsection{Research Thoughts}

Firstly, based on the predecessor's academic research results and current reality, this paper takes the growth environment and psychological characteristics of college students in the new era as a breakthrough point to investigate and survey the status quo of college students' ideal and belief. Secondly, in the light of new challenges and problems faced in the process of college students' ideal and belief education, the jointly management supporting system and coordination mechanism should be established. Thirdly, new ideas, methods, means and channels for upgrading the effects of college students' ideal and belief education should be put forward.

\subsection{Methodology}

With the above research thoughts, this paper adopts system analysis method, the combination of micro analysis with macro analysis, the combination of static and dynamic analysis to conduct a multidimensional research on college students' ideal and belief education.

A. System analysis. The work of ideal and belief education is not interpreted by linear thinking. It is a complex social system project with huge system and hierarchical network which consist of many sub systems such as education institutions, education subjects, education contents, education environments and so on. Therefore, in order to grasp and tackle the principal contradiction existing in the transition and perfection from disorder to order during the process of ideal and belief education, the coordination mechanism must be constructed from the perspective of system theory.

B. The combination of macro analysis and micro analysis. Not only the investigation of the background of the college students' ideal and belief formation process should be conducted from the macro level, but also the deeper research of the influence factors, supporting systems and coordination mechanism should be done from the micro level. The total investigation of macro level is helpful in the grasp of temporal-spatial logic in the college students' ideal and belief formation process. 
The deeper research of micro level can lay a strong theory foundation for college students' ideal and belief education. They complement mutually, support each other and benefit by associating together.

C. The combination of static analysis and dynamic analysis. The establishment of ideal and belief is a long term historical process, so the ideal and belief education is a deepening process step by step naturally. But, there exists relative stable state in the process. As a state, it reflects the sprouting, establishing and status quo of college students' ideal and belief which needs real time evaluation. As a process, it is not only a process of the establishing and developing of ideal and belief, but also is an integrating process of internalizing and establishing of the ideal and belief for college student individual. Therefore, the static investigation and dynamic analysis are required together in the research of college students' ideal and belief education in the new era.

\section{THE CONSTRUCTION OF COLLEGE STUDENTS' IDEAL AND BELIEF EDCATION SYSTEM}

\subsection{The New Challenges and Dilemma Faced by College Students' Ideal and Belief Education}

In the rapid development of globalization and internet era, more and more problems such as economic growth, social division, ecological and climate degradation, disease, conflict, etc. are emerging in the whole world put human society in a position of great changes unseen in a century. The negative effect of economic growth, constant infiltration of the variety of internet information, college students' inefficiency and wrong cognition on the ideal and belief, getting away further and further with traditional culture, etc.bring severe tests and shocks to college students' ideal and belief education in the new era. Therefore, there is an urgent need to respond all of these challenges and dilemma positively.

\subsection{The Supporting System of Joint Management for College Students' Ideal and Belief Education in the New Era}

Faced with the challenges of the new situation and huge changes, the education of college students' ideal and belief is undoubtedly a difficult and big social system project which demands the top-level design of the governments of all levels, united efforts of college functional departments, wide participation of all sectors of society, the infiltration of fine family style and rules, healthy, orderly and positive social environment, etc. With the input of all these social resources and power, perfect supporting system for education can be established to form a strong education position under the jointly managing regime. In order to make concerted efforts and work together in the process of education, all of the governments, universities, families and social environment must empower college students' ideal and belief education in the new era by positively finding their own function, position, responsibility, etc.

\subsection{The Coordination Mechanism of Joint Management for College Students' Ideal and Belief Education in the New Era}

The supporting system of joint management for college students' ideal and belief education is an integrated big system. In the system, how the sub systems run and cooperate with each other determines the real effect of college students' ideal and belief education. In order to make the the whole system working in a better and orderly state in which resultant force of education can be formed, education scheme, education subjects, education contents and education environment are demanded to construct a coordination mechanism. In the mechanism, the coordination of educational scheme is the basis, the coordination of educational subjects is the heart, the coordination of educational contents is the principal part, the coordination of educational environment is the guarantee.

In the above educational system, the main points are the construction of supporting system and coordination mechanism based on the perspective of joint management for college students' ideal and belief education in the new era. The difficulties existing in the construction of the supporting system and coordination mechanism are the building of social and network environment, and the coordination of educational subjects.

A. As the important outside supporting and guarantee system, social and network environment which connotation and extension are very extensive need to be defined and understood exactly and strictly. Without exact definition and strict understanding, the construction and supervision of social network environment cannot be conducted smoothly.

B. In the whole jointly managing system, because the construction of the coordination among the educational subjects involves multiple levels of subjects including governments, families, universities and their many sectors, how to determine and balance the role, status, division, responsibility and other related problems for each subject is a very important issue which is required repeated investigation and research. Without clear investigation and precise research, the role and function of each subject cannot be well defined and fully exploited. 


\section{CONCLUSION}

College students' ideal and belief education in the new era needs all-around and full process participation of the whole society to construct a jointly managing system. Obviously, it cannot be accomplished at one stroke because the work is a huge system project. Firstly, for the moment, starting from the new situation faced by college students' ideal and belief education, the education idea and cognition based on jointly managing education community and supporting system composed of governments, universities, families, society and environment should be formed as soon as possible. The idea of educational community based on common goal, mutual understanding and cooperation can help to form an atmosphere of performing their own functions and co-construction and co-cultivation, and can make up for shortcomings of colleges' leading role in the ideal and belief education at present. Secondly, the coordination mechanism which consists of educational scheme, educational subjects, educational contents and educational environments should be established to perfect the educational system construction and modify the one way and linear pushing mode with the fragmented and segmented operating and managing style in the process of ideal and belief education in the past. Thirdly, in order to create a jointly managing situation and enhance the education effects, the philosophy, concept, regime, method and channel of college students' ideal and belief education should be gradually innovated and perfected.

\section{REFERENCES}

[1] Yang Conglin, Wang Tao, Wang Qinghe. Research on construction of the education system of ideals and beliefs for college students in the new era, in: Education and Teaching Research. 2019(3), pp89-96,DOI:10.13627/j.cnki.cdjy.2019.03.011

[2] Shen Junqi. "Four-in-one" model and countermeasure for college students' ideal and belief education in the new era, in: Continue Education Research. 2018(8), pp69-74

[3] SU Yue, FAN Xin. Analysis on the needs and paths of college students' ideal and belief education in the new era, in: Journal of Hubei Open University. 2018(22), pp18-20,doi:10.3969 /j.issn.1671-5918.2018.22.009

[4] Zhao Qibo. Method innovation of strengthening college students' ideal and belief education in the new era, in: Future and Development. 2020(1), pp59-63,doi:10.3969/j.issn.1003-0166.2020.01.012

[5] Zhang Xuanxuan. Research on mechanism of college students' ideal and belief cultivation, in:
The Party Building and Ideological Education in Schools. 2020(2), pp64-66,

[6] Yan Chunchun. College students' ideals and faith education from the perspective traditional culture, in: Journal of College Advisor. 2012(3), pp28-31

[7] Liu Xihua. The effect of traditional culture on the "90 after" college students' ideals and faith education in: Science \& Technology Vision.2013(1), pp13-14

[8] Wang Na. The value and realization of traditional culture melting into college students' ideals and faith education, in: Ideological and Political Education Research. 2017(1), pp88-92, DOI:10.15938/j.cnki.iper.2017.01.018

[9] Zhang Sheqiang. Research on the path of college students' ideal and belief education in the new era, in: Journal of Changchun Normal University. 2019(9), pp9-12

[10] Ying Lin. Research on the path of college students' ideal and belief cultivation in the new era, in: Legal System and Society. 2019(4), pp192-193, DOI:10.19387/j.cnki.1009-0592.2019.04.207

[11] Cao Feng, Cao Qun. The theory logic and practicing path for college students' ideal and belief education in the new era, in: Studies in Ideological Education. 2020(2), pp134-137

[12] Wen Jinying. Discussion on the path of college students' ideal and belief cultivation in the new era, in: Legal System and Society. 2020(2), pp194-195,DOI:10.19387/j.cnki.1009-0592.2020.0 2.210

[13] Yao Fuqing. Exploration on the improving path for the effectiveness of college students' ideal and belief education in the epoch of omni-media, in: Educator (Hihger Education Forun). 2020(1), pp63-65

[14] Li Fanchang, et al. Theory and Method of Multidimentional Collaborative Education, in: Science Press. 2016.12 